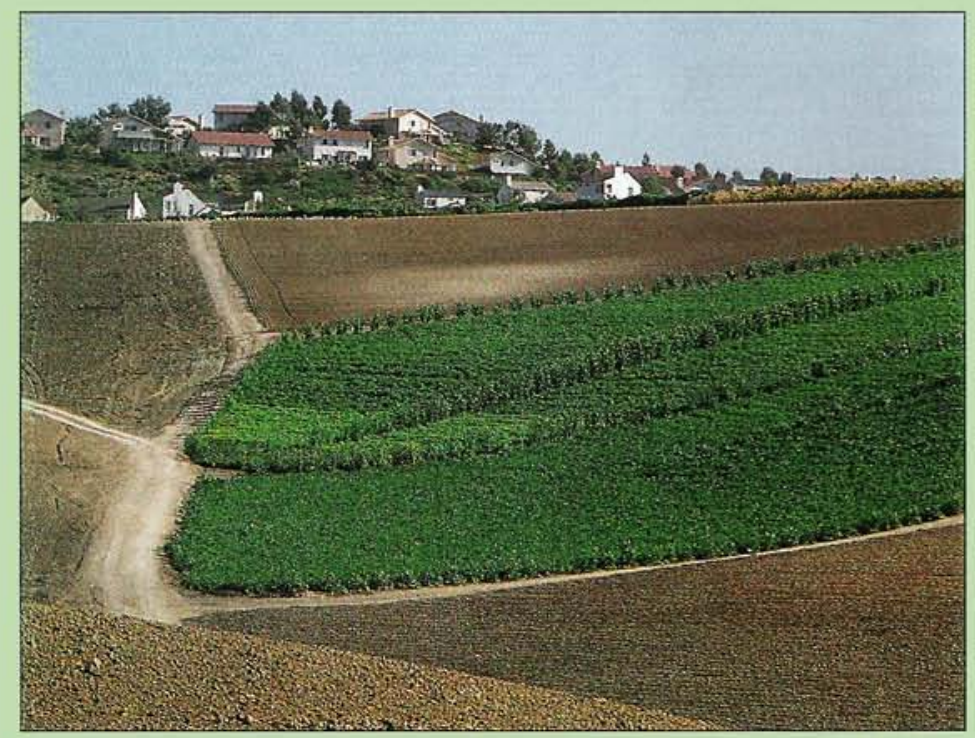

Housing developments and other forms of urban encroachment have replaced much of San Diego County's former farmland.

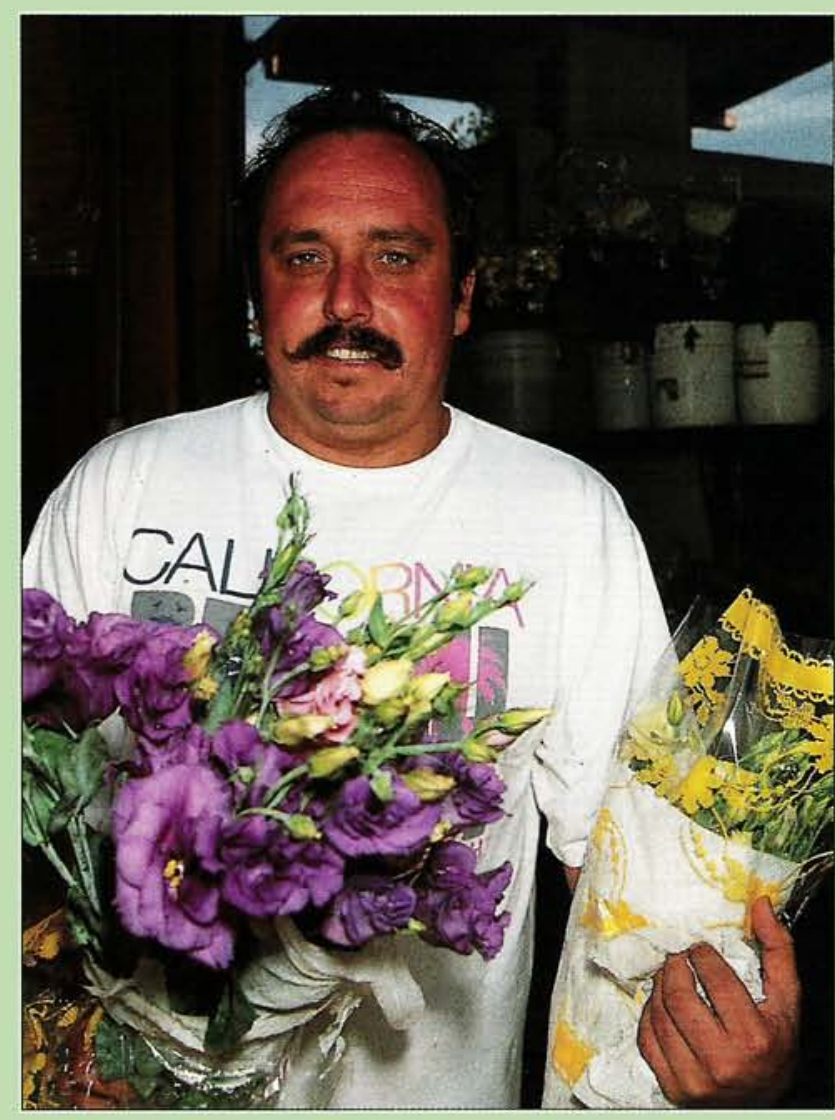

\section{San Diego farmers put 'sustainability' into practice}

Muñoz believes. "Sustainable is defined as staying in business," he says, "and in the 1990s they (small farmers) will have to learn how to farm without chemicals to stay in business."

Muñoz is apparently getting his message across. As of October 1992, San Diego County had 170 registered organic farmers - the highest number of any county in the state but still a tiny percentage of the county's estimated 3,000 small farms.

Muñoz, who worked as a youth on his family's Imperial Valley farm, has been cultivating his interest in organic production techniques since 1984, when he surveyed farmers to get a better idea of the crops they were raising, the size of their operations and their research needs.

Many farmers wanted to learn about organic farming, so in 1986 Muñoz embarked on sabbatic to study sustainable agriculture at the Alchemy Center in Massachusetts and the Rodale Institute in Pennsylvania. "We didn't have many resources to draw from," Muñoz says. "Most of the information came from outside the land grant system at that time."

His program has since grown to include seminars, conferences, research projects and publications on sustainable agriculture. Muñoz has also extended information to Spanish-speaking small farmers in special workshops. His educational
Above, Escondido grower Joe Rodriguez who with his brother Carlos owns and operates JR Organics. The brothers emphasize fresh cut flowers and organic vegetable production.

Below: In addition to their on-site insectary, the Rodriguezes employ cover crops and composted chicken manure (middle of picture) for fertilizer. Greenhouses are used to grow organic tomatoes early in the season.

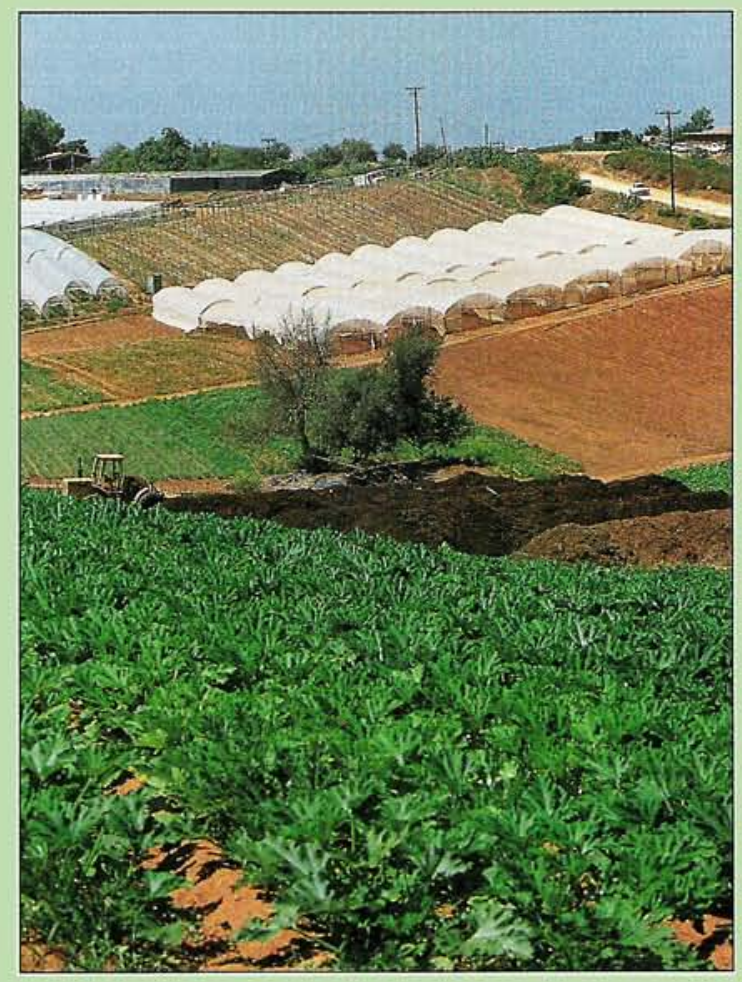




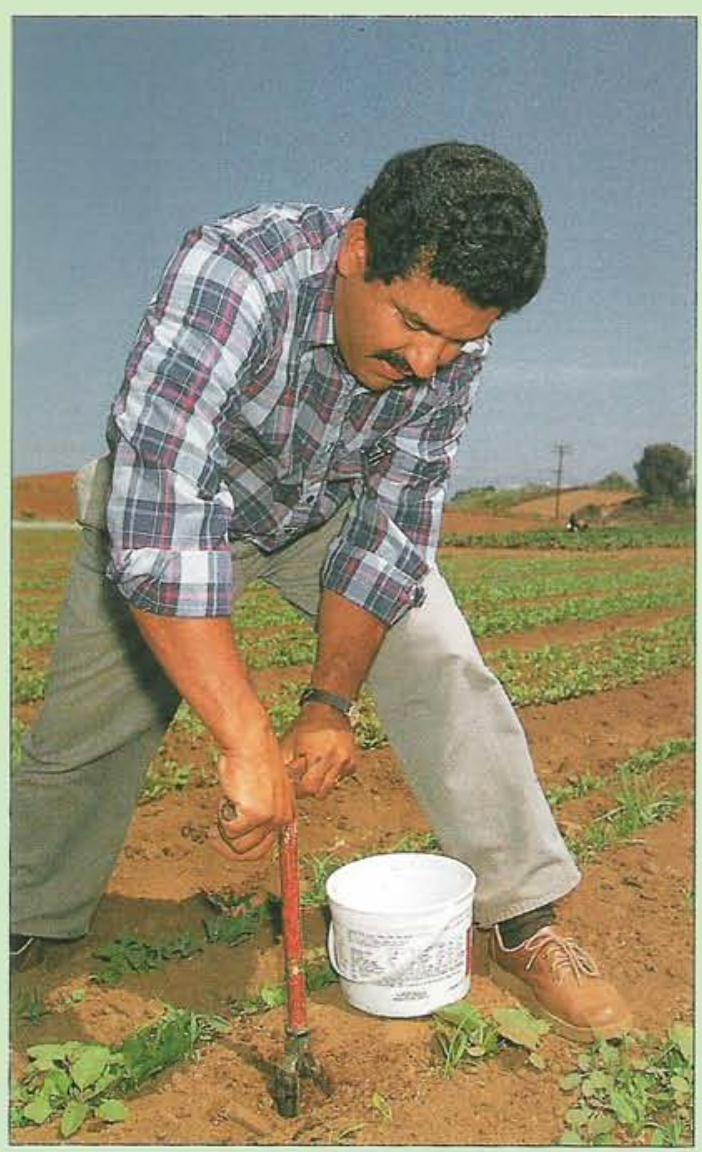

efforts earned him the 1991 American Farmland Trust agricultural conservation award for localized public education.

Muñoz is now developing a project to foster a socially, environmentally and economically sustainable niche for San Diego County's small farms. Working with Borevitz, other farmers and local community leaders, Muñoz wants to build a center where farmers can learn new techniques, consumers can buy locally grown produce, and schoolchildren can learn about where food comes from.

The guiding principle behind the project is a cooperative approach in which "members" invest time and/or money in exchange for farm-fresh food and smallscale farmers are guaranteed a reliable local market. It is called community-supported agriculture (CSA), and its proponents describe it as "a form of cooperation between farmers and consumers who come together to produce healthy food in a sustainable way."

Muñoz has applied for a grant from the Kellogg Foundation to begin the project. Once established, an advisory committee of small farmers, farm workers, consumers, community leaders, government agencies and Extension staff would steer such project activities as:

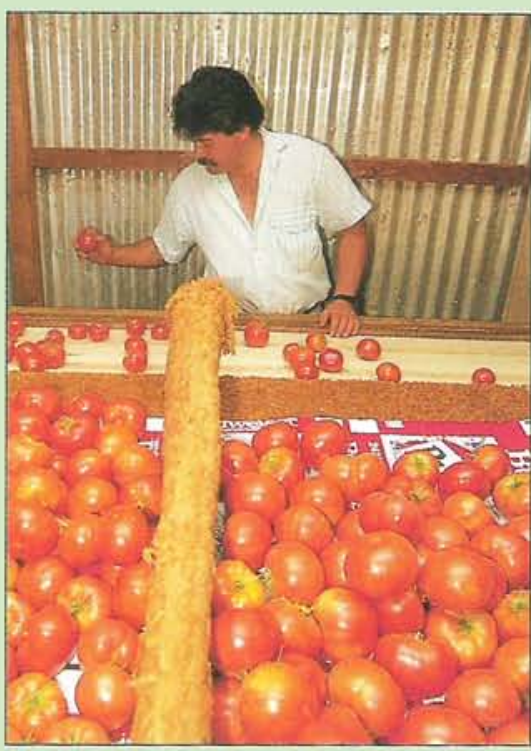

Above, Carlsbad farm worker sorts tomatoes in grower Francisco Valdivia's small, on-site packing house.

\section{Left, San Diego County Farm Advisor} Faustino Muñoz takes a soil sample from the JR Organics farm for a laboratory analysis. Recent seed germination problems may be linked to salt buildup from composted chicken manure; Muñoz has encouraged legume cultivation to diversify the farm's soil fertility program.

- A business plan and feasibility study for the regional produce market, farm demonstration site and agricultural science center.

-Educational programs for migrant farm workers and their families in nutrition, youth development, leadership training and pesticide safety.

- A farm worker organic garden with accompanying short courses and field demonstrations.

- Establishment of a direct marketing connection between an organic farm and an adjacent senior citizen community.

- Field demonstrations and seminars on sustainable and organic agricultural practices.

In the long term, Muñoz hopes, the project will result in a plan that protects the environment, provides high-quality local produce and supports the economic viability of small family farmers. The San Diego project reflects the progress made by proponents of sustainable agriculture.

"I like to think we've helped to take the myth out of it," Muñoz says. "Sustainable agriculture is no longer viewed as extremist. It's a more legitimate, acceptable and worthwhile goal. The program has also helped UC to define its role in sustainable agriculture in the state and nationally." - J. Stumbos

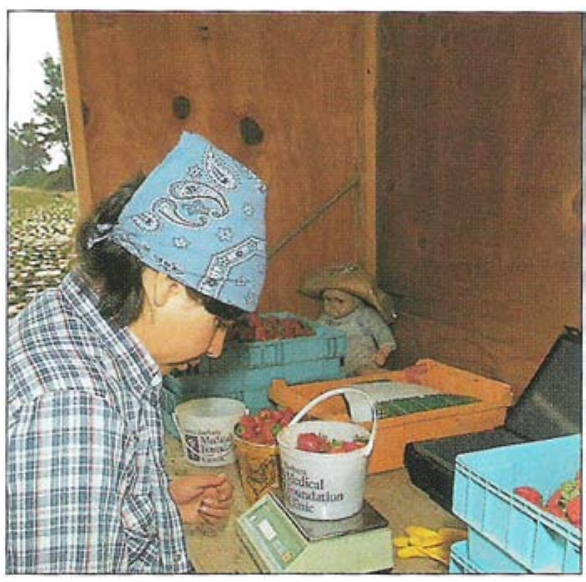

Harvesting technician Patricia Michel weighs fruit from a demonstration plot of UC-developed strawberries in the Santa Maria area.

\section{UC program (continued from p. 10)}

ally improved, small farm income has lagged, causing some families to seek offfarm employment and others to quit farming altogether.

Jiménez, whose area of expertise is specialty crops, conducts a broad-ranging research and education program on all aspects of crop production, management and marketing. He encourages some small-scale farmers, especially those growing grapes, tree fruit and nuts, to take advantage of the expertise offered by other advisors in the Tulare County office.

Jiménez has successfully developed control of the tomato pinworm (TPW), Kieferia lycopersicella, a major pest of cherry tomatoes that threatens to become an equally serious pest of other fresh market and processing tomatoes.

Damage occurs when TPW larvae burrow under the fruit's calyx, making it difficult to sort out infested fruit. Because growers cannot remove the calyx to detect damage, tolerance for the pest is virtually zero. Economic losses to small-scale farmers who produce most of the "cherries" has been devastating. Rather than risk unmarketable crops, many apply insecticides extensively - as much as 12 times in a season is not uncommon. In spite of this barrage, TPW damage is high, compounded by secondary outbreaks of another pest, the vegetable leafminer, Lyronmyza sativa.

With the help of a private company and other UC scientists, Jiménez began seeking an alternative to control the pest. Several years later, they developed a "pheromone confusion" technique that successfully disrupts the pest's reproductive cycle. The technique involves flooding a tomato field with the scent of female pinworms, frustrating the attempts of male pinworms to find mates.

\section{Louie Valenzuela}

More than a dozen years ago, when he graduated in agricultural economics, Louie 